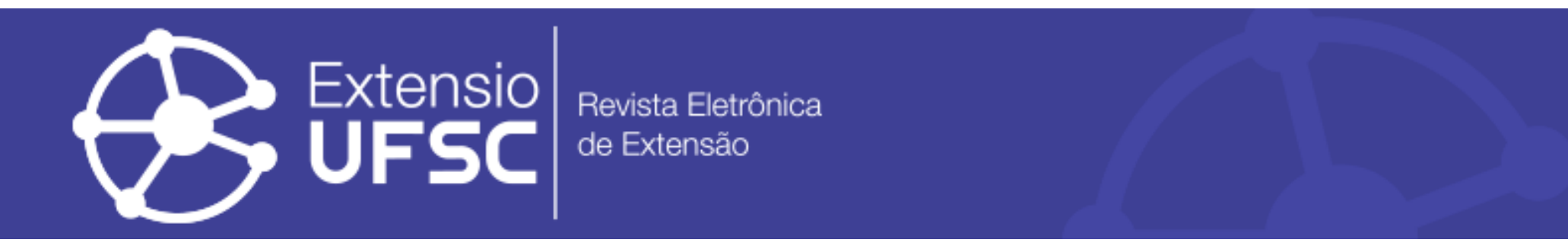

\title{
GESTÃO ESTRATÉGICA EM CLÍNICA DE FISIOTERAPIA - RELATO DE EXPERIÊNCIA EXTENSIONISTA
}

\author{
Lisandra de Andrade Dias \\ Universidade Federal de Santa Catarina \\ lisandra.andrade@gmail.com \\ Lana Dandara Silva Lima \\ Universidade Federal de Santa Catarina \\ lanadandara@gmail.com
}

\begin{abstract}
Resumo
Este artigo relata a experiência extensionista de alunos voluntários do curso de design da Universidade Federal de Santa Catarina - UFSC durante o período de 2015 e 2016. Visando reformular o direcionamento estratégico de uma pequena empresa local por meio da gestão do design, utilizou-se do método Design Thinking para estruturar o desenvolvimento deste projeto. Em sua conclusão, foram entregues: marca, plano de negócios e planejamento estratégico, documentos que embasaram o reposicionamento no mercado realizado durante esse período. Como fatores de sucesso, obteve-se uma maior prática dos conteúdos aprendidos dentro e fora da sala de aula, além da troca de conhecimentos entre equipe e cliente, fomentando o exercício da cocriação nas atividades de design.

Palavras-chave: Gestão Estratégica. Pequenas Empresas. Clínica de Fisioterapia. Design.
\end{abstract}

\section{STRATEGIC MANAGEMENT IN PHYSICAL THERAPY CLINIC - EXTENSIONIST EXPERIENCE REPORT}

\begin{abstract}
This article reports the extension experience of volunteer students of the design course of the Federal University of Santa Catarina - UFSC during the years of 2015 and 2016. In order to reformulate the strategic direction of a local small business with design management, the Design Thinking method was used to structure the development of this project. In conclusion, the following were provided: brand design, business plan ans strategic planning, documents that supported its repositioning in the market during this period. As success factors, the students experienced real-world practice of the contents learned in and out of the classroom, plus had knowledge exchange between team and client, fomenting the exercise of co-creation in design activities.
\end{abstract}

Keywords: Strategic Planning. Small Business. Physical Therapy Clinic. Design.

\section{GESTIÓN ESTRATÉGICA EN CLÍNICA DE TERAPIA FÍSICA - RELATO DE EXPERIENCIA EXTENSIONISTA}

Resumen

Este artículo relata la experiencia extensionista de alumnos voluntários del curso de diseño de la Universidad Federal de Santa Catarina - UFSC durante el período de 2015 y 2016. Con el propósito de reformular el direccionamiento estratégico de una pequeña empresa local a través de la gestión del diseño, se utilizó el método Design Thinking para estructurar el desarrollo de este proyecto. En su conclusión, fueron entregados: marca, plan de negócios y planificación estratégica, documentos que basaron el reposicionamiento en el mercado realizado durante ese período. Como factores de éxito, se obtuvo una mayor práctica de los contenidos aprendidos dentro y fuera del aula, además del intercambio de conocimientos entre equipo y cliente, fomentando el ejercicio de la cocción en las actividades de diseño.

Palabras clave: Planificación Estratégica. Pequeños Negocios. Clínica de Terapia Física. Diseño. 
Gestão estratégica em clínica de fisioterapia - relato de experiência extensionista

\section{INTRODUÇÃO}

As micros e pequenas empresas (MPEs) ocupam um papel de destaque no Brasil. Em 2014, existiam 9 milhões de MPEs que foram responsáveis por mais da metade dos empregos formais do país, representando $27 \%$ do PIB nacional e $40 \%$ da massa salarial brasileira. Em todos os setores elas possuem relevantes faixas de mercado e na área de serviços, são responsáveis por mais de um terço da produção nacional (36,3\%) (SEBRAE, 2014). Esse destaque na economia brasileira é percebido desde a década de 80, quando em 1985 já representavam 21\% de participação no PIB mantendo um crescimento estável desde então (SEBRAE, 2014).

Apesar do ambiente favorável que cada vez mais encontram, ainda existem dificuldades comuns que afetam as MPEs, sendo a informalidade inicial a maior delas. A maioria das empresas desse porte começa como pequenos empreendimentos que crescem e se desenvolvem, mas não avançam na gestão administrativa seguindo os padrões de mercado. Como resultado, surgem dificuldades que em várias situações acabam por impedir a evolução dessas empresas.

Entendendo a importância do crescimento desse setor e a escassez de consultorias de administração e gestão de design, este projeto teve como objeto de estudo a clínica de fisioterapia Projeto Coluna Reta, fundada em 1994 em Florianópolis na região sul do Brasil. Este caso chegou ao conhecimento da equipe de extensão, por meio da solicitação dos responsáveis pela clínica que necessitavam de apoio em seu processo de gestão. A fim de analisar seu funcionamento e estrutura, identificar pontos críticos a serem resolvidos e pontos de melhorias a serem trabalhados, este trabalho de extensão iniciado em 2015, teve como objetivo utilizar da gestão do design e ferramentas de marketing e design (SWOT, design thinking, imersão criativa) na solução das situações encontradas.

Composta por 6 proprietários (2 médicos e 4 fisioterapeutas) é uma clínica de reabilitação especializada que oferece as fisioterapias: individual (GDS - Método Godelieve Denys-Struyf / RPG - Reeducação Postural Global), em grupo (PCR - Projeto Coluna Reta), domiciliar e pilates. Suas atividades prezam pela qualidade e se diferenciam pelo atendimento personalizado e humanizado. Além dos pacientes regulares, as fisioterapeutas prestam serviço social gratuito para pessoas economicamente desfavorecidas.

Segundo depoimentos dos fundadores, no período em que a empresa foi formada não existia a grande oferta de clínicas de fisioterapia como observa-se atualmente. Além disso, considerando sua especialização na técnica de GDS, o Projeto Coluna Reta apresentava diferencial competitivo frente as concorrentes da área. No início deste trabalho de extensão, a clínica apresentava falhas nos processos de comunicação, de organização da equipe e dos espaços 
Gestão estratégica em clínica de fisioterapia - relato de experiência extensionista

para um maior aproveitamento do potencial que possuem. Mesmo com mais de 20 anos de existência, não possuía nenhum direcionamento estratégico e plano de negócios, nem investimentos em comunicação e marketing, dependendo exclusivamente da indicação de médicos e pacientes para a conquista de novos clientes. Pode-se notar a falta de softwares que realmente atendessem às necessidades da clínica e dos funcionários que os operavam, além de uma estrutura física que não auxiliava os seus pacientes. E acima de tudo, percebeu-se uma falta de foco dos sócios em relação às dificuldades e melhorias da clínica.

Como defendido por Mozota (2011), a gestão do design corresponde a identificação e comunicação das maneiras em que o design pode contribuir com a estratégia de uma empresa. A multidisciplinaridade intrínseca no design facilita compreensão e integração dos planos estratégico e operacionais, como defendem Stoner e Freeman (1985) ao afirmar que o design é crucial no processo de inovação, no qual as ideias se formam em território criativo e são moldadas às variáveis técnicas e demandas do mercado. A gestão do design não aparece para substituir as formas tradicionais de gerenciamento de corporações, ela existe para "agregar valor" e "apoiar a revisão de modelos mentais de empresas" (MOZOTA, 2011).

Complementando essa visão de desenvolvimento estratégico, este projeto de extensão utilizou do Design Thinking para pautar seu processo. A própria abordagem multidisciplinar da construção de projetos de design em organizações encontra suporte no Design Thinking. Definida pelas autoras Demarchi, Fornasier e Martins (2010) como 'pensar como um designer', ela foi criada para possibilitar e estimular a inovação durante a solução de problemas. Essa abordagem utiliza ferramentas e métodos comuns ao design, para gerar resultados que "integrem as necessidades do usuário, as possibilidades tecnológicas e o sucesso da organização" (BROWN, 2009). Dividida em 3 fases, a primeira delas - definição do problema - é o momento no qual a equipe se aproxima do cliente buscando compreender seu universo. Na segunda fase - geração de ideias - realiza-se a análise das informações e a criação de hipóteses e por fim, na terceira fase - Criação de formas - coloca-se em prática as observações aprendidas, testando e aprimorando os resultados até alcançar a solução final.

\section{MATERIAIS E MÉTODOS}

No segundo semestre de 2015 a equipe deste projeto de extensão - Revisão Cega 1, Revisão Cega 2, C.M, F.B., G.F. e H.M., se reuniram com o objetivo de aplicar o estudo prático da gestão do design no direcionamento estratégico da clínica de fisioterapia Projeto Coluna Reta com o uso do método Design Thinking (ilustração 1). 


\section{design thinking}

\section{DEFINIÇÃO DO PROBLEMA}

- ENTREVISTA BRIEFING

- ANGLUSE DE CONCORRENTES E SIMILARES

- ANGLLISE SWOT CRUZADA

- FuJugrama atividades da CLINICA

- JORNADA DO CUENTE

- PLANO DE NEGSCIOS

- PLANejamento estratégico

- EVENTO CRIATIVO

\section{GERAÇÃO DE IDEIAS}

- POSICIONAMENTO DE MERCADO

- AvauAçio DE ESTRUTURA

- NAMING

\section{CRIAÇÃO DE FORMAS}

Ilustração 1 - Metodologia Design Thinking e etapas do projeto. Fonte: O Autor, 2018.

Após estabelecido o cronograma de atividades no início de julho de 2015, iniciou-se a primeira etapa do projeto - Definição do problema - e realizaram-se entrevistas com os proprietários e principais funcionários da clínica e os participantes da equipe. Nesta fase extraiuse as informações de briefing, que deram base para compreender a real situação da empresa e o microambiente no qual está inserida. Nesse momento foram mapeados o fluxograma de atividades da clínica e a jornada do usuário paciente e, ainda como parte da análise inicial, foram avaliadas as empresas concorrentes diretas e indiretas mais relevantes (de acordo com os critérios: preço, localização e perfil do paciente) e o mercado de fisioterapia na cidade. Complementando estes estudos realizados, utilizou-se a ferramenta SWOT cruzada que, nativa do marketing e administração, analisa o ambiente interno e externo de uma empresa e resulta na criação de estratégias que visam a redução de riscos e o aumento das chances de sucesso do negócio. A chamada análise SWOT traz uma sigla vinda do inglês que se refere às Forças (Strenghts), Fraquezas (Weaknesses), Oportunidades (Opportunities) e Ameaças (Threats) da marca. Realizada em duas partes, primeiramente houve a construção da SWOT listando as informações recolhidas em toda a fase inicial do projeto seguida do cruzamento dos dados em quatro categorias: Vantagens Competitivas (Forças + Oportunidades), Capacidade de Defesa (Forças + Ameaças), Necessidade de Orientação (Fraquezas + Oportunidades) e Vulnerabilidades (Fraquezas + Ameaças).

Durante os meses de agosto e setembro daquele ano, a equipe de design iniciou o plano de negócios e o planejamento estratégico da empresa, este último desenvolvido junto à administradora responsável pela clínica. Em outubro, os integrantes do projeto reuniram-se com os stakeholders da empresa, proprietários, alguns funcionários e alguns clientes, para definir a missão, visão e valores que norteariam os próximos passos. Esse encontro chamado de Evento 
Gestão estratégica em clínica de fisioterapia - relato de experiência extensionista

Criativo, trabalhou a junção das opiniões internas e externas à clínica, para atingir ao máximo de veracidade na decisão da identidade organizacional do Projeto Coluna Reta. Ao final desse encontro, foi realizada uma pesquisa com os participantes buscando coletar os conceitos que mais descreviam a clínica, uma estratégia para direcionar a produção visual das próximas etapas. Em novembro, durante a etapa Geração de ideias, foi trabalhado o posicionamento de mercado da clínica, avaliando a estrutura física, fornecedores, naming e identidade visual utilizados até o momento.

No primeiro semestre de 2016, foi realizada a última etapa da metodologia - Criação de formas. Nela foi gerada e definida um novo sistema de identidade visual e manual de aplicação restrito no qual constava a papelaria institucional e sinalização interna e externa da empresa, que após a segunda etapa da metodologia, passou a se chamar Clínica Coluna Reta.

\section{RESULTADOS E ANÁLISES}

Destaca-se como resultado principal a otimização de processos da clínica decorrentes da reestruturação proposta e desenvolvida durante o projeto de extensão. Pelo âmbito da gestão estratégica, foi possível trazer à tona uma maior organização e conhecimento dos serviços oferecidos e melhora das atividades de cada funcionário, segundo os proprietários a administradores da clínica.

Nesse processo, evidencia-se a estruturação do plano de negócios nos padrões SEBRAE, que levantou questões administrativas nunca antes discutidas pelo corpo clínico. Para construção deste documento no qual é registrado detalhes e análises administrativas e estratégicas da empresa, a equipe pode estudar e compreender profundamente a clínica e auxiliar na elaboração de diversos componentes de sua identidade organizacional, como missão, visão e valores.

O planejamento estratégico desenvolvido em conjunto com a equipe profissional e administrativa do Projeto Coluna Reta, trouxe um resultado ainda mais abrangente já que foi possível tratar a gestão da empresa de maneira multidisciplinar. Realizado com a orientação do responsável administrativo da clínica, os alunos estudaram a teoria deste importante instrumento de gestão de empresas e colocaram em prática seu método de construção, coletando ao longo do primeiro semestre de trabalho as informações necessárias para seu preenchimento, analisando a realidade da clínica no momento do projeto e definindo objetivos e metas para os anos de 2016 e 2017 juntamente com propostas de ações de comunicação, design e promoção da marca.

Com o Evento Criativo, ferramenta de design, os integrantes participam de uma pratica em grupo com imersão criativa a fim de definir aspectos relacionados a identidade organizacional 
de uma empresa; os alunos do projeto de extensão tiveram a oportunidade de elaborar e conduzir o encontro com os stakeholders da clínica e trabalhar com pessoas de visões diferenciadas. Durante as dinâmicas realizadas nesse encontro, pode-se observar o engajamento dos participantes e seus variados níveis de conforto ao realizar atividades que não faziam parte do seu repertório. Desse momento, por meio da pesquisa com os participantes, foram extraídas as palavras conceito acolhedora/aconchegante, confiável, competente, ética/correta, profissional e respeitosa - que nortearam o desenvolvimento da nova identidade da clínica.

O reposicionamento da comunicação da clínica foi outro destaque dentre os resultados atingidos, visto que com as informações coletadas nas primeiras duas etapas do projeto, percebeu-se a necessidade de se estabelecer no mercado de forma diferenciada, buscando conquistar novos clientes e profissionais.

Oportunizando maior relevância acadêmica, os alunos foram responsáveis também pelo desenvolvimento de propostas de marca para a clínica. Nesta atividade, utilizou-se dos conceitos definidos nas etapas anteriores do projeto para geração de alternativas gráficas que traduzissem ao público-alvo a nova identidade organizacional definida. Após a criação e o refinamento, as opções desenvolvidas e apresentadas para a equipe da clínica, foram colocadas para avaliação pelo público cliente. Realizada de modo online, por meio da plataforma Typeform, funcionários, clientes e parceiros tiveram a oportunidade de indicar qual proposta de identidade visual mais se representava aos conceitos da empresa. Após o final do período de pesquisa, com 37 respostas coletadas, ambas alternativas se mostram condizentes com os requisitos de projeto elencados (como pode ser visto na ilustração 2).

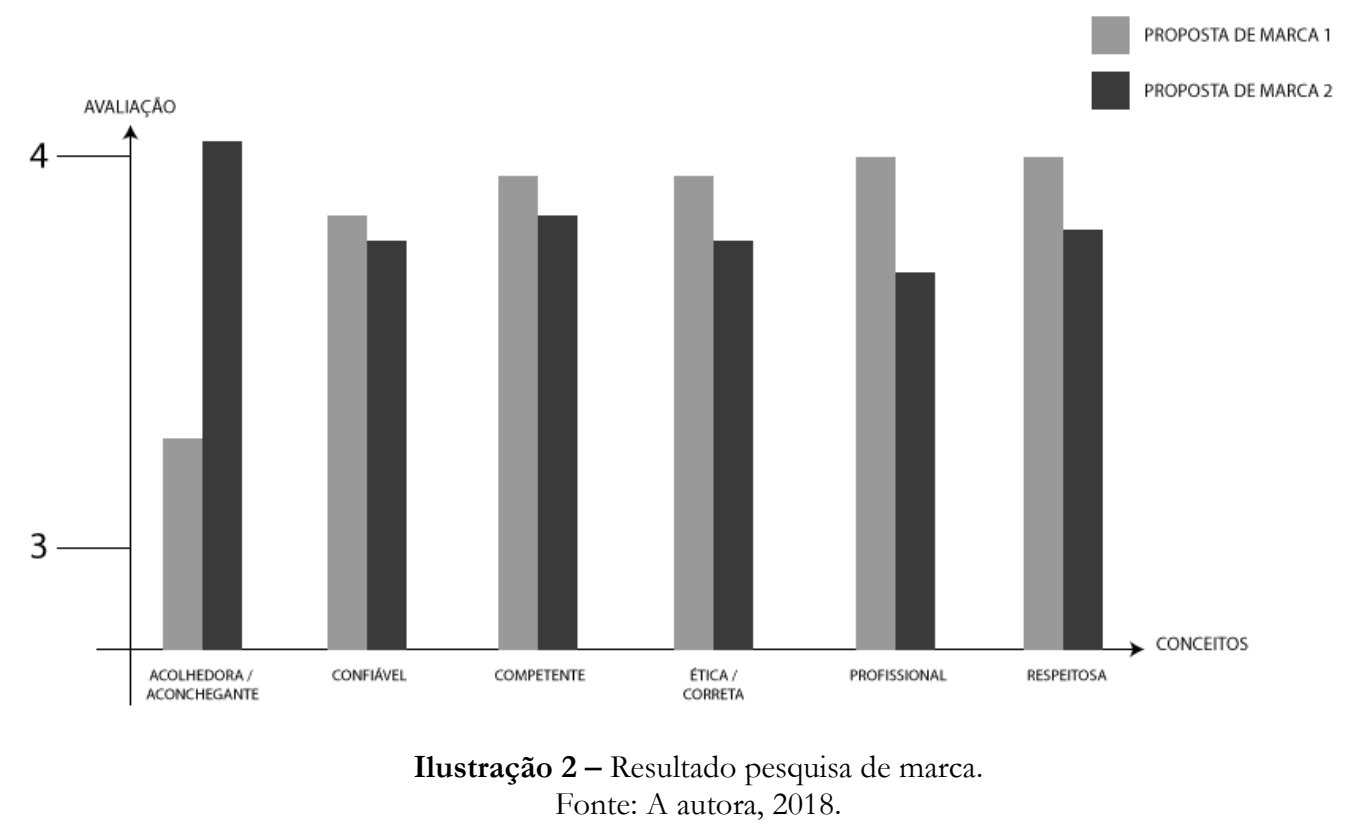


Gestão estratégica em clínica de fisioterapia - relato de experiência extensionista

Dessa forma, seguindo a abordagem de Design Thinking na qual o cliente participa ativamente do processo de criação, a equipe da clínica pode analisar novamente as opções de marca, optando pela expressava maior representatividade com seu negócio (conforme ilustração $3)$.
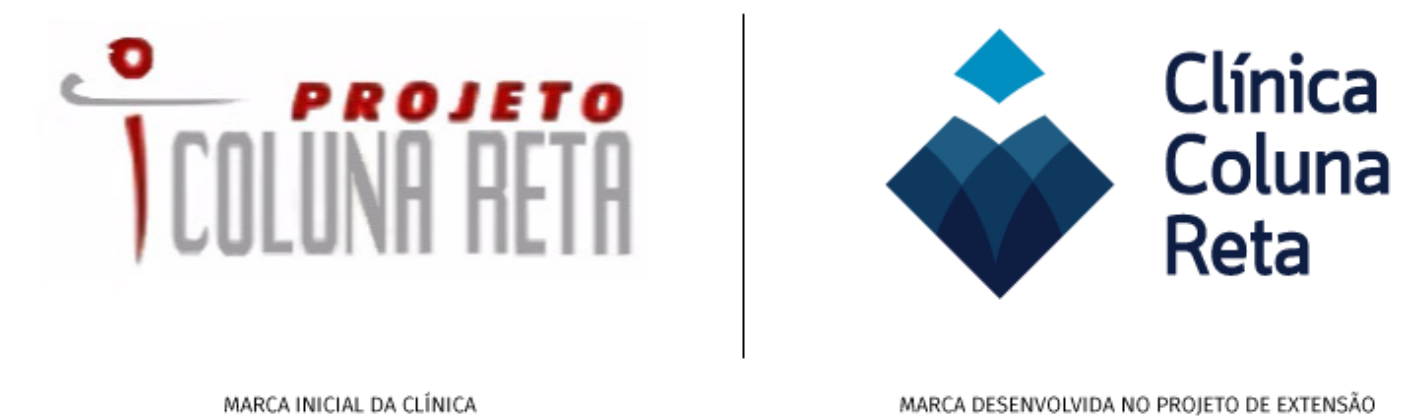

Ilustração 3 - Marca da clínica - antes e depois.

Fonte: A autora, 2018.

Além da marca, foi necessária a mudança do nome (de Projeto Coluna Reta para Clínica Coluna Reta) que, suportada pela identidade organizacional definida, representaria de forma mais adequada a clínica e sua nova proposta.

Em linhas gerais, um dos grandes fatores de sucesso do projeto de extensão aqui relatado, foi o envolvimento da equipe de designers com os agentes da própria clínica. A cocriação estabelecida entre os participantes foi crucial na obtenção dos resultados alcançados que garantiram uma base sólida para os desenvolvimentos futuros da empresa. Além de ter proporcionado aos integrantes da clínica um contato enriquecedor com a área do design.

\section{CONSIDERAÇÕES FINAIS}

Desempenhando o objetivo estabelecido, este projeto teve êxito em solucionar as necessidades solicitadas pelo cliente seguindo a ótica da gestão do design. Durante o decorrer do processo foram encontradas dificuldades na aplicação de melhorias à clínica, tanto por questões financeiras, estruturais ou pela intervenção dos sócios. Dessa forma, os resultados entregues foram gerados para se adequar ao máximo à realidade do cliente. Os materiais produzidos durante esse período (marca, plano de negócios e planejamento estratégico) foram aos poucos incorporados à rotina da clínica, de acordo com suas possibilidades e seguindo o planejamento estabelecido em conjunto com a equipe. 
Gestão estratégica em clínica de fisioterapia - relato de experiência extensionista

Este caso foi de suma importância para o crescimento acadêmico e profissional dos alunos que tiveram a oportunidade de participar deste projeto de extensão voluntário paralelo ao curso universitário de design, desenvolvendo um trabalho de médio porte para um cliente real. Durante os dois semestres de duração, os alunos puderam exercitar o fator multidisciplinar do design, praticando atividades que permeiam as disciplinas de design promocional, gestão de design, criação e gestão de marca e criação gráfica. Destaca-se também a contribuição dos alunos para o desenvolvimento dos potenciais administrativos e estratégicos da clínica cliente que presta serviços a pacientes economicamente desfavorecidos.

\section{REFERÊNCIAS}

BROWN, Tim. Change by Design. Nova Yorque: HarperCollins, 2009.

DEMARCHI, Ana Paula Perfetto; FORNASIER, Cleuza Bittencourt Ribas; MARTINS, Rosane Fonseca de Freitas. Processo de design com abordagem de design thinking. In: MARTINS, Rosane F. F; VAN der LINDEN, Júlio (org). Pelos Caminhos do Design: Metodologia do Projeto. Londrina: Eduel, 2012.

LOCKWOOD, Thomas. Design thinking: Integrating innovation, customer experience, and brand value. New York: Allworth Press, 2009

MOZOTA, Brigitte Borja de. Gestão do Design. Bookman, 2011.

PEÓN, Maria Luísa. Sistemas de identidade visual. Rio de Janeiro: 2AB, 2003.

SEBRAE. Disponível em: http://www.sebrae.com.br/sites/PortalSebrae/ufs/mt/noticias/ micro-e-pequenas-empresas-geram-27-do-pib-do-brasil,ad0fc70646467410VgnVCM2000003c 74010aRCRD. Acesso em 28. fev. 2018

STONER, J. A. F., FREEMAN, R. E. Administração. Rio de Janeiro: Prentice-Hall, 1985.

VIANNA, Maurício [et al.]. Design thinking: inovação em negócios. Rio de Janeiro: MJV Press, 2012.

Recebido em: 09/03/2018

Aceito em: 07/02/2019 